\title{
Maternal mycotoxin exposure and adverse pregnancy outcomes: a systematic review
}

\author{
Nicholas N. A. Kyei ${ }^{1,2}$ (D) Daniel Boakye ${ }^{3}$ Sabine Gabrysch ${ }^{1,4,5}$ \\ Received: 2 July 2019 / Revised: 18 December 2019 / Accepted: 20 December 2019 / Published online: 27 January 2020 \\ (C) The Author(s) 2020
}

\begin{abstract}
Mycotoxin exposure from food occurs globally but is more common in hot humid environments, especially in low-income settings, and might affect pregnancy outcomes. This study aimed to synthesize the evidence from epidemiological studies on the relationship between maternal or fetal exposure to different mycotoxins and the occurrence of adverse pregnancy outcomes. Multiple databases were systematically searched up to December 2018 to identify studies that assessed the association between mycotoxin exposure in pregnant women or fetuses and at least one pregnancy outcome. Studies were appraised and results were synthesized using standard methods for conducting systematic reviews. This review identified and included 17 relevant studies. There is some evidence to suggest that exposure to various Aspergillus mycotoxins (e.g., aflatoxin) during pregnancy may impair intrauterine fetal growth and promote neonatal jaundice. Findings were inconclusive concerning the influence of aflatoxin exposure on perinatal death and preterm birth. Only two studies assessed effects of maternal exposure to Fusarium mycotoxins (e.g., fumonisin) on adverse pregnancy outcomes. These studies found that maternal fumonisin exposure may be associated with hypertensive emergencies in pregnancy and with neural tube defects. Studies using grain farming and weather conditions as a proxy measure for mycotoxin exposure found that such exposure was associated with an increased risk of preterm birth and late-term miscarriage. In conclusion, there is already some evidence to suggest that exposure to mycotoxins during pregnancy may have detrimental effects on pregnancy outcomes. However, given the limited number of studies, especially on effects of Fusarium mycotoxins, more studies are needed for a more comprehensive understanding of the effects of different mycotoxins on maternal and fetal health and to guide public health policies and interventions.
\end{abstract}

Keywords Pregnant women $\cdot$ Mycotoxins $\cdot$ Aflatoxins $\cdot$ Adverse pregnancy outcome

\section{Introduction}

The etiology of adverse pregnancy outcomes, such as miscarriage, preterm birth, low birth weight (LBW), and birth small-

Nicholas N. A. Kyei

nicholas.kyei@uni-heidelberg.de

1 Unit of Epidemiology and Biostatistics, Heidelberg Institute of Global Health, Heidelberg University, Im Neuenheimer Feld 324, 69120 Heidelberg, Germany

2 Public Health Division, 37 Military Hospital, Accra, Ghana

3 Division of Clinical Epidemiology and Aging Research, German Cancer Research Center (DKFZ), Im Neuenheimer Feld 581, 69120 Heidelberg, Germany

4 Research Department 2, Potsdam Institute for Climate Impact Research, Potsdam, Germany

5 Institute of Public Health, Charité - Universitätsmedizin Berlin, Berlin, Germany for-gestational-age (SGA), is multifactorial and not fully understood. Besides parity, maternal infection, hypertensive disease in pregnancy, and smoking as well-known risk factors (Kramer 2003), insufficient maternal nutrition has an undisputed impact on the outcome of pregnancies, as well as on the well-being of newborns (Kramer 2003; Ota et al. 2014). Furthermore, foods consumed by expectant mothers may contain hazardous natural products like mycotoxins. Mycotoxins are low-molecular-weight secondary metabolites of filamentous molds or micro-fungi that are toxic to vertebrates and other animals, even in low concentrations (Bennett and Klich 2003). Several hundreds of compounds are considered mycotoxins, but few are considered major threats to human and animal health, including aflatoxins (AFs), fumonisins (FBs), ochratoxin A (OTA), deoxynivalenol (DON), and zearalenone (ZEN) (Bennett and Klich 2003; Richard 2007; Smith et al. 2012). These mycotoxins are produced by a wide range of fungal species and often contaminate nuts, grains, and spices, especially in hot humid environments conducive 
to fungal growth (Chan-Hon-Tong et al. 2013). In general, Aspergillus mold strains produce AFs and OTA, while Fusarium mold strains produce FBs, DON, and ZEN (Bennett and Klich 2003; Smith et al. 2012).

Globally, mycotoxins contaminate an estimated $25 \%$ of cereal crops (CAST 2003) and due to their resistance to food processing and cooking practices, they are an almost ubiquitous exposure in cereal-consuming populations, especially in low-income countries (IARC 2015). In many of these settings with favorable environmental conditions for mold contamination, poor harvesting practices and improper storage of cereals and spices are common and food insecurity is widespread (FAO 2019). This is often coupled with less stringent food safety regulations and systems to protect consumers, leading to the consumption of highly contaminated foods with potentially serious health consequences (Bennett and Klich 2003).

Chronic exposure to AFs, the most widely studied mycotoxins, is a known risk factor for liver cancer (Turner et al. 2012) and has also been associated with low fertility in men (Shuaib et al. 2010a). Chronic exposure to FBs has been linked to esophageal cancer (Alizadeh et al. 2012; Chu and Li 1994; Wang et al. 2000), while OTA exposure is associated with kidney disease (Abid et al. 2003; Hope and Hope 2012; Raghubeer et al. 2017). Epidemiological studies from different regions have shown that mycotoxin exposure is widespread in pregnant women and newborns (Abdulrazzaq et al. 2002; Chan-Hon-Tong et al. 2013; Groopman et al. 2014; Jonsyn et al. 1995). This potentially harmful exposure during the critical first 1000 days of life of a child (Groopman et al. 2014) may be responsible for malnutrition and various adverse health outcomes (Etzel 2014). While maternal and infant exposure to AFs has, for instance, been shown to be associated with maternal anemia (Shuaib et al. 2010b), growth faltering (Gong et al. 2004; Turner et al. 2007), and severe acute malnutrition in children (McMillan et al. 2018), little is known about the effects of other mycotoxins and combinations of different mycotoxins on adverse pregnancy outcomes. This study therefore aimed to systematically review and synthesize the available evidence from epidemiological studies on the relationship between maternal mycotoxin exposure and adverse pregnancy outcomes.

\section{Materials and methods}

\section{Literature search}

A systematic literature search was conducted in six major databases including PubMed, Web of Science, Ovid-Medline(R), Ovid-EMBASE, Ovid-MIDIRS (Maternity and Infant Care), and Ovid-AMED (Allied and Complementary Medicine), without language restrictions, to identify relevant studies up to December 8, 2018. The review question was defined using the
PECO (population, exposure, comparator, and outcome) framework (Morgan et al. 2018) as follows: "P: Among pregnant women or fetuses, what is the effect of; E: Detection of higher levels of different mycotoxins during pregnancy versus; $\mathrm{C}$ : No detection or lower levels of mycotoxins during pregnancy on; $\mathrm{O}$ : Specific adverse pregnancy and/ or newborn health outcomes." For PubMed, the following search strategy was used, incorporating Text Words (TW) and Medical Search Headings (MeSH), and combining appropriate terms on pregnancy and pregnancy outcomes with terms on mycotoxins:

(("pregnant women" [tw] OR pregnancy [tw] OR preg-
nancy [mesh] OR mothers [tw] OR fetus* [tw] OR fetal
[tw] OR fetal [mesh]) AND ("pregnancy outcome*"
[tw] OR "pregnancy outcome" [mesh] OR miscarriage
[tw] OR abortion [tw] OR prematurity [tw] OR "pre-
term birth" [tw] OR "preterm delivery"[tw] OR "low
birthweight" [tw] OR "birth weight" [tw] OR "birth
defect*"[tw] OR "fetal death" [tw] OR fetal death
$[$ mesh] OR "stillbirth" [tw])) AND ("fungal
toxin*"[tw] OR aflatoxin*[tw] OR mycotoxin*[tw]
OR mycotoxins [tw] OR mycotoxin*[mesh]).

For the search in Web of Science, instead of using text words and MeSH terms, a topic-specific search (TS) was conducted using the same search terms as above. For the Ovid database searches, a search was conducted using the same search terms as above combined with appropriate Boolean logic operators, incorporating the multiple field search (MP) and explosion (XM) function, as required. Additional searches for gray literature with the Google Scholar search engine, as well as cross-referencing, were conducted by manually searching bibliographies of the included articles for additional eligible studies. Finally, the search strategies for PubMed and Web of Science were saved and set up to receive automatic updates of new results. This systematic review was conducted in accordance with PRISMA guidelines (Liberati et al. 2009).

\section{Study selection}

Studies were eligible for inclusion in this review if they (a) were published original observational studies or trials that assessed the effects of maternal (pregnant woman or fetal) exposure to mycotoxins (AFs, FBs, DON, OTA, ZEN etc.) on pregnancy outcomes (e.g. miscarriage, preterm birth, LBW and SGA) and (b) reported the association between maternal mycotoxin exposure and adverse pregnancy outcome(s) with an appropriate quantitative effect measure. Two reviewers (NNAK, DB) screened the titles and abstracts of identified articles to assess their eligibility for inclusion using the aforementioned criteria. Full texts of potentially relevant studies were obtained for further assessment. Studies that examined the prevalence of mycotoxins or of pregnancy outcomes only 
but not their association were excluded, as well as studies on the effects of mycotoxins more generally without a specific focus on maternal exposures and pregnancy outcomes. Relevant articles published as abstracts or posters only were also excluded because the amount of information was not sufficient for quality assessment.

\section{Methodological quality assessment and descriptive synthesis of results}

Two investigators (NNAK, DB) extracted data from eligible studies independently from each other, using a pre-coded data extraction form. This included the basic characteristics of the included studies and information on methodological quality assessment, as reported in Table 1. A descriptive synthesis of included study results was then performed, as reported in Table 2. In case several different adjusted effect measures were presented in a study, the measures with the larger number of adjustment variables were extracted.

A modified Newcastle-Ottawa Scale for observational studies (Wells et al. n.d.) was used to assess the quality and risk of bias of the included studies. Two investigators (NNAK and DB) independently assessed each of the eligible studies against the following criteria: (a) representativeness of the sample, evaluated by the use of a random sampling method (b) valid and reliable exposure assessment, (c) valid and reliable ascertainment of outcomes, and (d) measurement of and adjustment for at least one key potential confounding variable in the multivariable models for observational studies. Each domain was awarded one point, giving a total of four achievable points - low scores indicate low quality and high risk of bias. Disagreements in the data extraction or quality assessment were resolved through further review and comprehensive discussion.

\section{Results}

\section{Literature search}

A total of 347 studies were identified through the systematic search. After excluding duplicates $(n=142)$, the remaining 204 studies were screened and 17 studies were then retained for full text review (Fig. 1). Of these, one

Table 1 Characteristics of studies on mycotoxins and adverse pregnancy outcomes

\begin{tabular}{|c|c|c|c|c|c|c|c|c|c|c|c|}
\hline \multirow[t]{2}{*}{ First author } & \multirow[t]{2}{*}{ Year } & \multirow[t]{2}{*}{ Country } & \multirow[t]{2}{*}{ Study design } & \multirow[t]{2}{*}{ Exposure assessment method } & \multicolumn{2}{|c|}{ Sample size } & \multicolumn{5}{|c|}{ Quality assessment* } \\
\hline & & & & & Women & Infants & $\mathrm{RE}$ & EA & $\mathrm{OA}$ & $\mathrm{AD}$ & Score \\
\hline De Vries & 1989 & Kenya & Prospective cohort & HPLC & 184 & 92 & 0 & 1 & 1 & 0 & 2 \\
\hline Maxwell & 1994 & Nigeria & Cross-sectional & HPLC & - & 625 & 0 & 1 & 1 & 0 & 2 \\
\hline Jonsyn & 1995 & Sierra Leone & Cross-sectional & HPLC & 71 & 64 & 0 & 1 & 1 & 0 & 2 \\
\hline Sodeinde & 1995 & Nigeria & Case-control & HPLC & 87 & 330 & 0 & 1 & 1 & 1 & 3 \\
\hline Ahmed & 1995 & Nigeria & Historical cohort + Case-control & HPLC & - & $78^{\mathrm{a}} ; 124^{\mathrm{b}}$ & 0 & 1 & 1 & 0 & 2 \\
\hline Kristensen & 1997 & Norway & Historical cohort & N/A-Census data & - & 253,768 & 1 & 0 & 1 & 1 & 3 \\
\hline Abulu & 1998 & Nigeria & Cross-sectional & TLC & 164 & 164 & 0 & 1 & 1 & 0 & 2 \\
\hline Kristensen & 2000 & Norway & Historical cohort & N/A-Census data & 56,720 & 52,062 & 1 & 0 & 1 & 1 & 3 \\
\hline Moodley & 2001 & South Africa & Case-control & HPLC & 51 & - & 0 & 1 & 1 & 0 & 2 \\
\hline Abdulrazzaq & 2002 & UAE & Cross-sectional & HPLC & 201 & 201 & 0 & 1 & 1 & 0 & 2 \\
\hline Abdulrazzaq & 2004 & UAE & Historical cohort & HPLC & 166 & 166 & 1 & 1 & 1 & 0 & 3 \\
\hline Missmer & 2006 & USA & Case-control & HPLC & 409 & - & 1 & 1 & 1 & 1 & 4 \\
\hline Nordby & 2006 & Norway & Historical cohort & N/A-Census data & 4912 & - & 1 & 0 & 1 & 1 & 3 \\
\hline Turner & 2007 & Gambia & Prospective cohort & ELISA & 138 & 138 & 0 & 1 & 1 & 1 & 3 \\
\hline Shuaib & 2010 & Ghana & Cross-sectional & HPLC & 785 & - & 0 & 1 & 1 & 1 & 3 \\
\hline Carlos & 2014 & Mexico & Case-control & N/A-dietary information & 513 & - & 0 & 0 & 1 & 0 & 1 \\
\hline Lauer & 2018 & Uganda & Prospective cohort & HPLC & 236 & 232 & 1 & 1 & 1 & 1 & 4 \\
\hline
\end{tabular}

UAE United Arab Emirates, USA United States of America, N/A not applicable, HPLC high-performance liquid chromatography, TLC thin layer chromatography, ELISA enzyme-linked immunosorbent assay

${ }^{\text {a }}$ Sample size for cohort

${ }^{\mathrm{b}}$ Sample size for case-control

$* \mathrm{RE}=$ Recruitment of study participants $(0=$ convenience/ non-random; $1=$ random sampling method $) ; \mathrm{EA}=$ Exposure assessment $(0=$ subjective; $1=$ objective); $\mathrm{OA}=$ Outcome assessment $(0=$ subjective; $1=$ objective $) ; \mathrm{AD}=$ Adjustment for relevant factors $(0=$ no adjustment; $1=$ at least one key potential confounding variable adjusted) 
Table 2 Summary of findings on maternal mycotoxin exposure and adverse pregnancy outcomes

\begin{tabular}{|c|c|c|c|c|c|c|c|}
\hline Author & Year & $N$ & Mycotoxin(s) & $\begin{array}{l}\text { Exposure } \\
\text { assessment } \\
\text { time }\end{array}$ & $\begin{array}{l}\text { Source of } \\
\text { specimen }\end{array}$ & $\begin{array}{l}\text { Pregnancy } \\
\text { outcome(s) }\end{array}$ & Results \\
\hline De Vries & 1989 & 208 & $\begin{array}{l}\text { Aflatoxins: } \\
\text { - } \mathrm{AFB}_{1} \\
\text { - } \mathrm{AFM}_{1} \\
\text { - } \mathrm{AFM}_{2}\end{array}$ & $\begin{array}{l}\text { - Prenatal } \\
\text { - Perinatal }\end{array}$ & $\begin{array}{l}\text { - Maternal } \\
\text { blood } \\
\text { - Cord blood }\end{array}$ & - Birth weight & $\begin{array}{l}\text { - AF was detected in } 53 \% \text { of maternal blood } \\
\text { samples in concentrations from } 12 \text { to } \\
11,574 \mathrm{pg} / \mathrm{ml} \text {, and in } 37 \% \text { of cord blood } \\
\text { samples in concentrations from } 17 \text { to } \\
6819 \mathrm{pg} / \mathrm{ml} \text {. } \\
\text { - Mean birth weight of female infants of } \\
\text { AF-positive mothers was } 255 \mathrm{~g} \text { lower than } \\
\text { that of females born to AF-negative mothers. } \\
\text { - Mean birth weight of male infants of } \\
\text { AF-positive mothers was } 132 \mathrm{~g} \text { higher than } \\
\text { that of males born to AF-negative mothers. } \\
\text { - There was an interaction between sex and AF in } \\
\text { maternal blood at delivery on birth weight } \\
\text { (ANOVA } p=0.020 \text { ). }\end{array}$ \\
\hline Jonsyn & 1995 & 64 & $\begin{array}{l}\text { Aflatoxins: } \\
\text { - } \mathrm{AFB}_{1} \\
\text { - } \mathrm{AFM}_{1} \mathrm{M}_{2} \\
\text { - } \mathrm{AFG}_{1} \mathrm{G}_{2} \\
\text { - Aflatoxicol } \\
\text { Ochratoxin A }\end{array}$ & $\begin{array}{l}\text { - Postnatal } \\
\text { - Perinatal }\end{array}$ & $\begin{array}{l}\text { - Cord blood } \\
\text { - Maternal } \\
\text { blood }\end{array}$ & $\begin{array}{l}\text { - Birth weight } \\
\text { - LBW }\end{array}$ & $\begin{array}{l}\text { - AF was detected in } 91 \% \text { and OTA in } 25 \% \text { of } \\
\text { cord blood in concentrations from } 4 \text { to } \\
9000 \mathrm{pg} / \mathrm{ml}(\mathrm{AF}) \text { and } 200 \text { to } 3500 \mathrm{pg} / \mathrm{ml} \\
(\mathrm{OTA}) \text {. } \\
\left.\text { - } \mathrm{AFM}_{1}(56 \%) \text {, aflatoxicol ( } 53 \%\right) \text {, and } \mathrm{AFG}_{2} \\
(41 \%) \text { were the most frequently detected } \\
\text { aflatoxins. } \\
\text { - AF was also detected in } 6 \text { out of the } 8 \text { maternal } \\
\text { blood samples analyzed. } \\
\text { - LBW occurred in } 17.2 \% \text { of deliveries and was } \\
\text { associated with higher prevalence of AF, and } \\
\text { with significantly higher levels of AFM } \mathrm{AF}_{2} \\
\text { ( } p<0.05 \text { ) and AFG }(p<0.04) \text {. } \\
\text { - AF levels in normal birth weight babies were } \\
\text { higher in girls than in boys. } \\
\text { - OTA levels were higher in LBW babies } \\
\text { compared to normal weight babies ( } 0.5 \text { vs } \\
0.9 \text { ng/ml; } p=0.06) \text {. } \\
\text { - Exposure to AF or OTA had no effect on the } \\
\text { birth weight of boys. Mean birth weight of } \\
\text { exposed girls was } 190 \mathrm{~g} \text { lower than of } \\
\text { unexposed girls. }\end{array}$ \\
\hline Sodeinde & 1995 & 407 & $\begin{array}{l}\text { Aflatoxins: } \\
\text { - } \mathrm{AFB}_{1} \\
\text { - } \mathrm{AFM}_{1} \mathrm{M}_{2} \\
\text { - } \mathrm{AFG}_{1} \mathrm{G}_{2} \\
\text { - Aflatoxicol }\end{array}$ & - Postnatal & $\begin{array}{l}\text { - Infant blood } \\
\text { - Maternal } \\
\text { blood }\end{array}$ & $\begin{array}{r}\text { - Neonatal } \\
\text { jaundice }\end{array}$ & $\begin{array}{l}\text { - } \mathrm{AF} \text { was detected in } 27.4 \% \text { of jaundiced babies } \\
\text { and } 17.0 \% \text { of their mothers, and in } 16.6 \% \text { of } \\
\text { control babies and } 14.4 \% \text { of their mothers. } \\
\text { - } \mathrm{AFB}_{1} \text { was the most frequently detected } \\
\text { aflatoxin and aflatoxicol was only detected in } \\
\text { jaundiced babies. } \\
\text { - AF was associated with higher prevalence of } \\
\text { neonatal jaundice (adj OR } 2.68 ; 95 \% \text { CI } \\
1.18-6.10 \text { ). }\end{array}$ \\
\hline Ahmed & 1995 & 202 & $\begin{array}{l}\text { Aflatoxins: } \\
\text { - } \mathrm{AFB}_{1} \\
\text { - } \mathrm{AFM}_{1} \mathrm{M}_{2} \\
\text { - } \mathrm{AF} \mathrm{G}_{1} \mathrm{G}_{2} \\
\text { - Aflatoxicol }\end{array}$ & - Postnatal & $\begin{array}{l}\text { - Cord blood } \\
\text { - Infant } \\
\text { peripheral } \\
\text { blood }\end{array}$ & $\begin{array}{r}\text { - Neonatal } \\
\text { jaundice }\end{array}$ & $\begin{array}{l}\text { - AF was detected in } 30 \% \text { of cord blood overall. } \\
\text { - AF was detected in } 38 \% \text { of cord blood of babies } \\
\text { who developed jaundice in concentrations } \\
\text { from } 13 \text { to } 238,177 \mathrm{pg} / \mathrm{ml} \text { and in } 23 \% \text { of } \\
\text { babies who did not develop jaundice in } \\
\text { concentrations from } 32 \text { to } 2654 \mathrm{pg} / \mathrm{ml} \\
(p=0.22) \text {. } \\
\text { - Later in neonatal life, AF was detected in } \\
24.3 \% \text { of peripheral blood of babies who } \\
\text { developed jaundice in concentrations from } 24 \\
\text { to } 23,749 \mathrm{pg} / \mathrm{ml} \text { and in } 30 \% \text { of babies who did } \\
\text { not develop jaundice in concentration from } 51 \\
\text { to } 3151 \mathrm{pg} / \mathrm{ml}(p=0.76) \text {. }\end{array}$ \\
\hline
\end{tabular}


Table 2 (continued)

\begin{tabular}{lllllll}
\hline Author & Year $N$ & Mycotoxin(s) & $\begin{array}{l}\text { Exposure } \\
\text { assessment } \\
\text { time }\end{array}$ & $\begin{array}{l}\text { Source of } \\
\text { specimen }\end{array}$ & $\begin{array}{l}\text { Pregnancy } \\
\text { outcome(s) }\end{array}$ & Results
\end{tabular}

$\begin{aligned} \text { Abulu } \quad 1998 \quad 164 & \text { Aflatoxins: } \\ & \cdot \mathrm{AFB}_{1} \mathrm{~B}_{2} \\ & \cdot \mathrm{AFG}_{1}\end{aligned}$

Kristensen $2000 \quad 56,720$ Grain farming plus weather conditions as proxy for mycotoxin exposure

\begin{tabular}{|c|c|c|c|}
\hline Moodley & 2001 & 51 & $\begin{array}{l}\text { Fumonisin } \\
\cdot \mathrm{FB}_{1}\end{array}$ \\
\hline Abdulrazzaq & 2002 & 201 & $\begin{array}{l}\text { Aflatoxins: } \\
\text { - } \mathrm{AFB}_{1} \\
\text { - } \mathrm{AFM}_{1} \\
\text { - } \mathrm{AFM}_{2}\end{array}$ \\
\hline
\end{tabular}

Abdulrazzaq $2004 \quad 166$ Aflatoxin - AFM1

- Prenatal

Horticultural agricultur- - Male al census urogenital data defects

a) Hypospadia

b) Cryptorchidism

Maternal
blood

- Eclampsia

- Postnatal Cord blood

- Birth weight - Gestational age
- Mean AF concentrations were not higher in jaundiced than in non-jaundiced neonates $(p=0.87)$.

- AF was detected in $70 \%$ of cord blood samples.

- $\mathrm{AFB}_{1}$ and $\mathrm{B}_{2}$ were the most frequently detected aflatoxins.

- AF was detected in $80 \%$ of cord blood of jaundiced neonates and in $36 \%$ of cord blood of non-jaundiced neonates $(p=0.0004)$.

- Male and female neonates with detectable AF and jaundice had lower birth weight than those without $\mathrm{AF}$ or jaundice (mean birth weight $55 \mathrm{~g}$ lower for males and $41 \mathrm{~g}$ for females, $p<0.05)$.

- Late-term miscarriage was more frequent in grain farmers with several seasonal fungal warnings as compared to those with one or no warnings (2 warnings: adj PR 1.80; 95\% CI $1.1-2.9 ; \geq 3$ warnings: adj $P R=2.60 ; 95 \% \mathrm{CI}$ $1.60-4.30)$.

- Hypospadia was more frequent in grain farmers with $\geq 2$ seasonal fungal warnings vs $<2$ warnings (adj PR 1.80; 95\% CI 0.90-3.40).

- Cryptorchidism was more frequent in grain farmers with $\geq 2$ seasonal fungal warnings vs $<2$ warnings (adj $\mathrm{PR}=1.2 ; 95 \% \mathrm{CI}$ $0.60-2.40)$.

- Fumonisin was detected in all maternal blood samples.

- Mean blood fumonisin levels were higher in pre-eclamptic $(0.45 \pm 0.17 \mu \mathrm{g} / \mathrm{ml} ; p=0.009)$ and much higher in eclamptic pregnant women $(2.85 \pm 0.08 \mu \mathrm{g} / \mathrm{ml} ; p<0.001)$ compared to normotensive women $(0.32 \pm 0.08 \mu \mathrm{g} / \mathrm{ml})$.

- AF was detected in $71 \%$ of cord blood samples.

- Prevalence and range of $\mathrm{AFM}_{1}, \mathrm{AFM}_{2}$ and $\mathrm{AFB}_{1}$ were $53 \%, 15 \%$, and $35 \%$, and concentrations ranged from 110 to $4060 \mathrm{pg} / \mathrm{ml}, 210$ to $3700 \mathrm{pg} / \mathrm{ml}$ and 228 to $15,225 \mathrm{pg} / \mathrm{ml}$, respectively.

- Significant negative correlation $(r=-0.63$; $p<0.001)$ between AF levels and birth weight.

- Reported no correlation between AF levels and gestational age.

- $\mathrm{AF}$ was detected in $68 \%$ of maternal blood in concentrations from 30 to $8490 \mathrm{pg} / \mathrm{ml}$ and in $67 \%$ of cord blood in concentrations from 50 to $10,440 \mathrm{pg} / \mathrm{ml}$.

- Strong correlation between cord and maternal levels of $\mathrm{AFM}_{1}(r=0.80 ; p=0.001)$.

- Strong negative associations between maternal $\mathrm{AFM}_{1}$ and birth weight $(r=-0.654$. $p<0.001)$ and between cord $\mathrm{AFM}_{1}$ and birth weight $(r=-0.565 ; p=0.001)$.

- No evidence for a difference in incidence of jaundice between AFM-positive and -negative babies $(15 \%$ vs. $13 \%, p=0.69)$. 
Table 2 (continued)

\begin{tabular}{|c|c|c|c|c|c|c|c|}
\hline Author & Year & $N$ & Mycotoxin(s) & $\begin{array}{l}\text { Exposure } \\
\text { assessment } \\
\text { time }\end{array}$ & $\begin{array}{l}\text { Source of } \\
\text { specimen }\end{array}$ & $\begin{array}{l}\text { Pregnancy } \\
\text { outcome(s) }\end{array}$ & Results \\
\hline Nordby & 2006 & 4912 & Grain farming & - Prenatal & $\begin{array}{l}\text { Horticultural } \\
\text { and } \\
\text { agricultur- } \\
\text { al census } \\
\text { data }\end{array}$ & Pre-eclampsia & $\begin{array}{l}\text { - Pre-eclampsia was higher in animal farmers } \\
\text { (aRR } 1.14,95 \% \text { CI } 1.07-1.22 \text { ) and lower in } \\
\text { grain farmers (aRR } 0.93,95 \% \text { CI } 0.86-1.01 \text { ) } \\
\text { compared to no animal and grain farmers re- } \\
\text { spectively. } \\
\text { - Pre-eclampsia was also lower in any year with } \\
\text { two or more fungal forecasts appearing (RR } \\
0.90,95 \% \text { CI } 0.84-0.97 \text { ) compared to years } \\
\text { with no fungal forecasts. }\end{array}$ \\
\hline Turner & 2007 & 138 & $\begin{array}{l}\text { Aflatoxin: } \\
\text { - } \mathrm{AFB}_{1}\end{array}$ & $\begin{array}{l}\text { - Prenatal } \\
\text { - Postnatal }\end{array}$ & $\begin{array}{l}\text { - Maternal } \\
\text { blood } \\
\text { - Cord blood }\end{array}$ & $\begin{array}{l}\text { - Birth weight } \\
\text { - Weight gain } \\
\text { - Height gain }\end{array}$ & $\begin{array}{l}\text { - AF was detected in all maternal blood samples } \\
\text { in concentrations from } 4.8 \text { to } 260 \mathrm{pg} / \mathrm{mg} \text { and } \\
\text { in } 48 \% \text { of cord blood samples in concentra- } \\
\text { tions from } 5.0 \text { to } 89.6 \mathrm{pg} / \mathrm{mg} \text {. } \\
\text { - Weak positive correlation between cord and } \\
\text { maternal levels of AF ( } r=0.383, p<0.001) \text {. } \\
\text { - Infants from mothers with above median AF } \\
\text { levels weighed } 34 \mathrm{~g} \text { less than infants with } \\
\text { lower median maternal AF levels ( } p=0.54) \text {. } \\
\text { - Maternal AF was a strong predictor of infant } \\
\text { weight and height gain (adj- } \beta-0.249, p=0.012 \text {; } \\
\text { adj- } \beta-0.207, p=0.044) \text {. }\end{array}$ \\
\hline Shuaib & 2010 & 785 & $\begin{array}{l}\text { Aflatoxin: } \\
\text { - } \mathrm{AFB}_{1}\end{array}$ & - Perinatal & $\begin{array}{c}\text { - Maternal } \\
\text { blood }\end{array}$ & $\begin{array}{l}\text { - LBW } \\
\text { - SGA } \\
\text { - Preterm birth } \\
\text { - Stillbirth }\end{array}$ & $\begin{array}{l}\text { - AF was detectable in all maternal blood } \\
\text { samples in concentrations ranging } \\
0.44-268.73 \mathrm{pg} / \mathrm{mg} \text {. } \\
\text { - Non-significant positive association between } \\
\text { highest quartile of maternal aflatoxin and SGA } \\
\text { (adj OR 1.23, 95\% CI 0.67-2.27), preterm } \\
\text { birth (adj OR 1.30, 95\% CI 0.75-2.27), and } \\
\text { stillbirth (adj OR 1.35, 95\% CI 0.52-3.50). } \\
\text { - Significant positive association between "very } \\
\text { high" maternal aflatoxin level and LBW (adj } \\
\text { OR }=2.09 ; 95 \% \text { CI 1.19-3.68). }\end{array}$ \\
\hline Lauer & 2018 & 220 & $\begin{array}{l}\text { Aflatoxin: } \\
\text { - } \mathrm{AFB}_{1}\end{array}$ & - Prenatal & $\begin{array}{c}\text { Maternal } \\
\text { blood }\end{array}$ & $\begin{array}{l}\text { - LBW- Small } \\
\text { head size } \\
\text { - Underweight- } \\
\text { Stunting- } \\
\text { Gestational } \\
\text { age }\end{array}$ & $\begin{array}{l}\text { - AF was detected in all maternal blood samples. } \\
\text { - Elevated maternal AF levels were associated with } \\
\text { LBW (adj- } \beta-0.07 ; 95 \% \text { CI }-0.13 \text { to }-0.003 \text {; } \\
p=0.040 \text { ) and lower head circumference } Z \text {-score } \\
\text { (adj- } \beta-0.23 ; 95 \% \mathrm{CI}-0.43 \text { to }-0.03 \text {; } \\
p=0.023 \text { ) at birth. } \\
\text { - Non-significant association between maternal } \\
\text { AF levels and infant length (adj- } \beta-0.10 ; 95 \% \\
\text { CI }-0.42 \text { to } 0.22 ; p=0.53 \text { ), WLZ (adj- } \beta \\
-0.15 ; 95 \% \mathrm{CI}-0.40 \text { to } 0.11 ; p=0.27), \mathrm{LAZ} \\
\text { (adj- } \beta-0.07 ; 95 \% \mathrm{CI}-0.24 \text { to } 0.10 ; p=0.41 \text { ) } \\
\text { and gestational age at birth (adj- } \beta-0.07 ; 95 \% \\
\text { CI }-0.41 \text { to } 0.26 ; p=0.66 \text { ). }\end{array}$ \\
\hline
\end{tabular}

$N$ sample size, $A F$ aflatoxin, $F B$ fumonisin, $O T A$ ochratoxin A, $L B W$ low birth weight, $N T D$ neural tube defect, $S G A$ small-for-gestational age, $O R$ odds ratio, $P R$ prevalence ratio, $R R$ relative risk, sa:so sphinganine-sphingosine ratio, $W L Z$ weight-for-length $z$-scores, $L A Z$ length-for-age $z$-scores, $A d j$ adjusted, ANOVA analysis of variance, $C I$ confidence interval

study was excluded as it was only an editorial commentary. One additional eligible study was retrieved from hand searching. In total, 17 studies were included and appraised in this review. Eleven were on AFs alone, one was on AFs and OTA, two were on FBs, and three used grain farming and weather conditions as a proxy for mycotoxin exposure in general. None of the studies investigated the effect of DON or ZEN. 


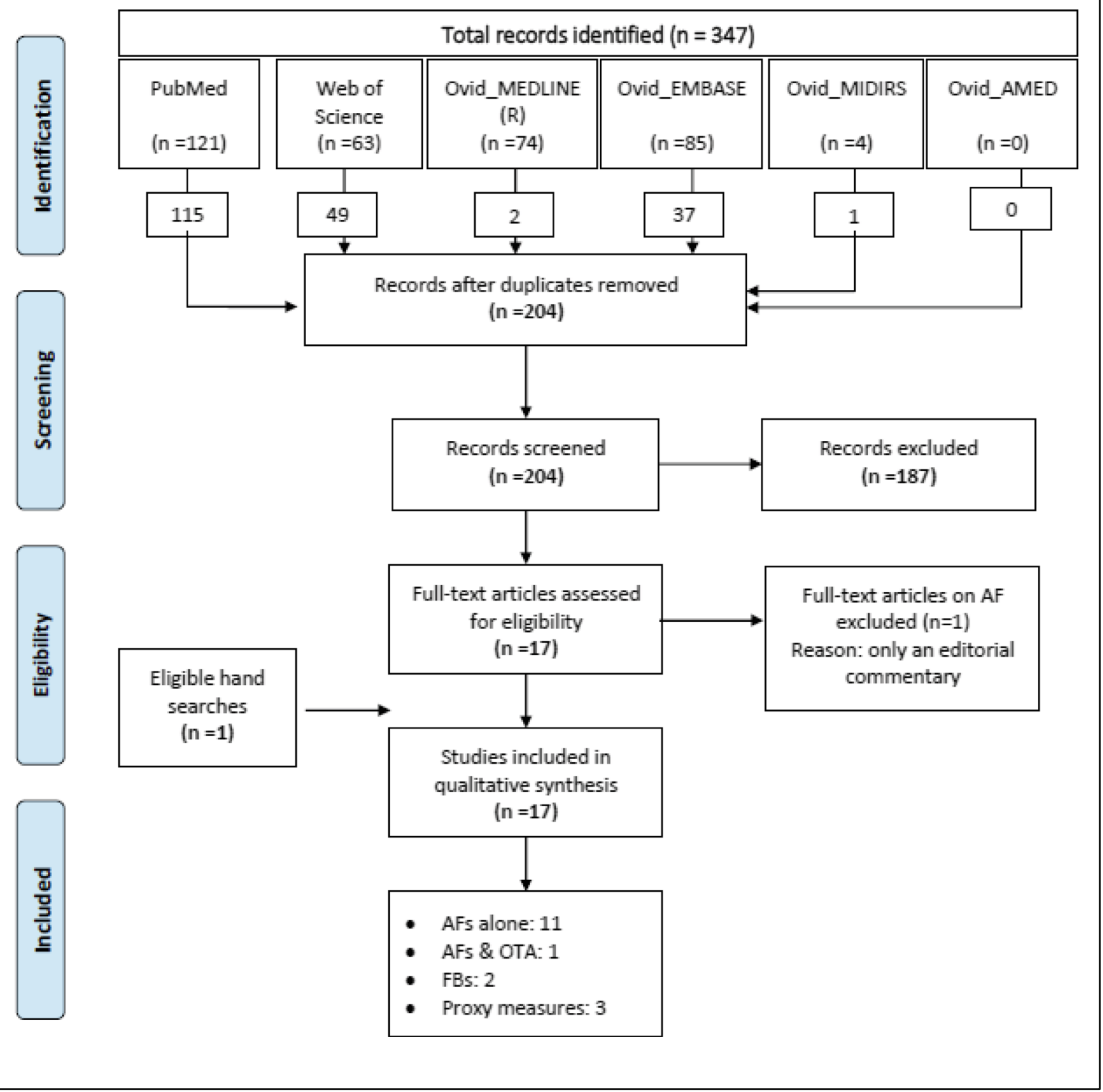

Fig. 1 PRISMA flow diagram showing selection of the included studies. AFs aflatoxins, OTA ochratoxin A, FBs fumonisins

\section{Characteristics of the included studies}

The 17 included studies were published between 1989 and 2018 (Table 1). The majority (10 studies) were conducted in the sub-Saharan African region (4 in Nigeria and 1 each in The Gambia, Sierra Leone, Ghana, Kenya, Uganda, and South Africa). Three further studies were from Europe, two from North America (United States and Mexico), and two were conducted in the United Arab Emirates. The studies employed cross-sectional (5/17), case-control (5/17), and cohort designs (8/17; of which 5 historical and 3 prospective). Only 5 studies reported the age of study participants and these included women in the reproductive age range of 15-45 years (Lauer et al. 2018; Missmer et al. 2006; Moodley et al. 2001; Nordby et al. 2006; Shuaib et al. 2010c). Out of a total quality score of 4 , the median score for the included studies was 3, with an interquartile range (IQR) of 2 to 3 .

Four studies used either information on agricultural/ weather conditions or a validated aflatoxigenic food frequency questionnaire to assess maternal mycotoxin exposure, while most studies (13/17) quantitatively measured mycotoxin exposure; 11 of these used high-performance liquid chromatography (HPLC) often with fluorescence detection. Over half of the studies (9/17) assessed mycotoxins from maternal 
blood samples: four on the first antenatal visit (between 18 and 24 weeks of gestation) and five during the postnatal period. About half (5/9) of these studies also assessed mycotoxins from cord or infant blood samples. The remaining four studies that quantitatively measured mycotoxin exposure assessed mycotoxins either from cord blood or infant blood samples.

The median detection frequency of mycotoxins in maternal blood samples was $87 \%$, with detection levels ranging between $17 \%$ and $100 \%$. The median reported detection frequency of mycotoxins in infant blood samples was $48 \%$, with reported levels ranging from $15 \%$ to $91 \%$. The adverse pregnancy outcomes investigated were intrauterine growth restriction (10 studies), neonatal jaundice (4 studies), miscarriage, stillbirth or perinatal death (3 studies), pre-eclampsia (2 studies), spontaneous preterm birth (1 study), and birth defects (1 study).

\section{Mycotoxin exposures and pregnancy outcomes}

Overall, ten studies were identified that evaluated the effects of maternal or fetal exposure to AFs on the occurrence of intrauterine growth restriction, which was mainly operationalized as lower mean birth weight (7 out of 10) and LBW (5 out of 10; Table 2).

Two studies examining mean birth weight found a negative correlation $(r=-0.63$ and -0.57$)$ between AF exposure and birth weight (Abdulrazzaq et al. 2002, 2004), while three other studies reported lower mean birth weight (with the difference ranging from $34 \mathrm{~g}$ to $70 \mathrm{~g}$ ) for infants with detectable $\mathrm{AF}$ levels (Abulu et al. 1998; Maxwell et al. 1994) or elevated maternal AF levels above median (Turner et al. 2007). A further study found a negative relationship only among female infants (with evidence for interaction) (De Vries et al. 1989). Only one study evaluated the joint effect of AFs and OTA on birth weight. Even though they reported no effect of the combined toxins on birth weight of boys, the mean birth weight of exposed girls was significantly lower (by $190 \mathrm{~g}$ ) than that of unexposed girls (Jonsyn et al. 1995). All five studies that assessed effects on LBW found a positive association $\left(\mathrm{OR}_{\text {range }}=1.07\right.$ to 2.29) between $\mathrm{AF}$ exposure and incidence of LBW babies (Abdulrazzaq et al. 2004; Carlos et al. 2014; Jonsyn et al. 1995; Lauer et al. 2018; Shuaib et al. 2010c).

Additionally, findings were suggestive of AF exposure triggering the development of neonatal jaundice. Two out of four studies found that the odds of $\mathrm{AF}$ exposure were more than two-fold (e.g. aOR $=2.68$; 95\% CI 1.18-6.10) in jaundiced neonates compared to non-jaundiced neonates (Abulu et al. 1998; Sodeinde et al. 1995). While the other two also found a higher incidence of neonatal jaundice among infants with $\mathrm{AF}$ exposure, these findings were also compatible with no difference between groups (Abdulrazzaq et al. 2004; Ahmed et al. 1995).
All three studies that evaluated the effect of a blood AF biomarker on gestational age or preterm birth found a higher likelihood of these outcomes among the exposed, but findings were also compatible with no difference (Abdulrazzaq et al. 2002; Lauer et al. 2018; Shuaib et al. 2010c).

No study on the effect of AF exposure on fetal loss or miscarriage was identified, but one study from Ghana found $35 \%$ higher odds of stillbirth at the highest level of maternal $\mathrm{AF}$ exposure, with a wide confidence interval, compatible with a more than three-fold increase and a halving of stillbirth $(\mathrm{aOR}=1.35 ; 95 \%$ CI $0.52-3.50)$ (Shuaib et al. 2010c). The three large Norwegian studies that used grain farming and seasonal fungal warnings based on weather conditions as a proxy measure of mycotoxin exposure, found that such an exposure was associated with increased mid-pregnancy deliveries (gestational age 21-24 weeks; OR $=1.58$; 95\% CI 1.192.09) and late-term miscarriage (gestational age 16-27 weeks; $\mathrm{OR}=1.31 ; 95 \% \mathrm{CI} 1.11-1.55)$ but found no association with perinatal death $(\mathrm{OR}=1.05 ; 95 \%$ CI $0.97-1.13)$ (Kristensen et al. 1997, 2000; Nordby et al. 2006). In contrast, a study from Mexico using aflatoxigenic food consumption as an exposure measure, found a positive association between maternal consumption of such foods with neonatal death $(\mathrm{OR}=2.35$; 95\% CI 1.43-3.86) (Carlos et al. 2014).

One of the Norwegian studies using proxy measures for mycotoxin exposure also investigated hypospadia and cryptorchidism, urogenital birth defects among males, as outcomes. They found that these defects were more frequent (PR-hypospadia 1.80; 95\% CI 0.90-3.40; PR-cryptorchidism 1.2; 95\% CI 0.60-2.40) among children of grain farmers who were exposed to two or more fungal warnings in the season of conception compared to those exposed to one or no warnings, but findings were also consistent with no difference between groups (Kristensen et al. 2000).

Only two studies were identified on maternal FB exposure and adverse pregnancy outcomes (Missmer et al. 2006; Moodley et al. 2001). The study by Missmer et al. (2006) estimated maternal blood FB level using the blood sphinganine/ sphingosine (sa:so) ratio. This ratio was associated with an increased risk of neural tube defects $\left(\mathrm{OR}_{\text {range }} 1.5\right.$ to 4.5) such as spina bifida up to a threshold of sa:so ratio of 0.35 , beyond which fetal death was more likely (Missmer et al. 2006). The study by Moodley et al. (2001) found that mean blood FB levels were lowest in normotensive pregnant women $(0.32 \pm 0.08 \mu \mathrm{g} / \mathrm{ml})$, higher in pre-eclamptic women $(0.45 \pm 0.17 \mu \mathrm{g} / \mathrm{ml})$, and substantially higher in eclamptic $(2.85 \pm 0.08 \mu \mathrm{g} / \mathrm{ml})$ pregnant women (Moodley et al. 2001). In contrast, the study by Nordby et al. (2006) in Norway that used proxy measures for mycotoxin exposure (Nordby et al. 2006) found no association between grain farming and preeclampsia (aRR $=0.93 ; 95 \%$ CI $0.86-1.01)$ but did find an association between animal farming and pre-eclampsia $(\mathrm{aRR}=1.14 ; 95 \%$ CI $1.07-1.22)$. 


\section{Discussion}

In this systematic review, the aim was to synthesize the available evidence from epidemiological studies on the effects of maternal or fetal exposure to mycotoxins on the occurrence of adverse pregnancy outcomes. Overall, this review found relatively few studies on the topic. The majority of studies focused on AF exposure, and results suggest detrimental effects of AFs on various pregnancy outcomes. Only two studies investigated the effects of Fusarium mycotoxins and found links to hypertensive emergencies of pregnancy and neural tube defects. Although exposure to multiple mycotoxins simultaneously is probably very common, only one study investigated the combined effect of AFs and OTA on intrauterine growth restriction.

The high mycotoxin levels detected in maternal and infant blood samples in the reviewed studies signify that mycotoxin exposure during pregnancy is widespread. Given this, the relatively limited number of studies identified in this review is concerning. The 17 studies were published within an almost 30-year span (between 1989 and 2018), with only three studies published in the last decade. Despite the wide geographic distribution of the included studies covering four of the six WHO world regions (Africa, Americas, Europe and EasternMediterranean), it is noteworthy that no study was from the Southeast Asia region despite a large number of human mycotoxin biomonitoring studies in this region (Ali et al. 2016; Escriva et al. 2017). In Bangladesh, for example, human biomonitoring is common (Ali et al. 2016; Escriva et al. 2017) and studies show a high prevalence of mycotoxins among pregnant women (Ali et al. 2015, 2017), but the potential harmful effects on pregnancy outcomes have not been studied yet.

The methodological quality of the included studies is fairly good despite some notable limitations. For example, most studies (11/17) did not describe the population from which the study participants were selected or the criteria for selecting the analytic sample. Furthermore, because all the included studies were observational and many did not adjust for important factors such as maternal age and socioeconomic status, the possibility of residual confounding cannot be excluded. Nonetheless, all the included studies used an objective and reliable method for assessing adverse pregnancy outcomes and the majority (13 out of 17) also used standard quantitative methods for measuring mycotoxin exposure. The blood biomarkers used for AFs, for example, do not only provide an objective estimate of mycotoxin exposure but also provide an estimate of prior recent exposure (Turner et al. 2012). This is particularly important as it helps to establish temporality even in a cross-sectional or case-control design. Nevertheless, biomarker analyses are not a perfect way for assessing mycotoxin exposure, as blood levels depend on several factors, including characteristics of the specific toxin being measured, such as its bioavailability in tissues or biologic fluids and its detection window. As the detection window of most toxins is very narrow, only recent exposures can be accurately quantified, leading to the possibility of a misclassification error in relation to the etiologically relevant exposure, which may bias the results towards the null value. All the studies on AFs, however, used the blood biomarkers which reflect exposure over the previous 2 to 3 months (Turner et al. 2012). It is also unfortunate that hardly any of the included studies comprehensively described their exposure assessment, including information on volume of blood analyzed, limit of detection and limit of quantitation, and other specifics of the detection method used. This hampers reproducibility and detailed comparison of results. Additionally, most of the studies dichotomized the exposure based on the detection limit and did not study the effect of different levels of exposure, precluding the assessment of dose-response relationships.

\section{Aspergillus mycotoxins and adverse pregnancy outcomes}

Three studies so far evaluated the effect of a blood AF biomarker on gestational age or preterm birth or on stillbirth (Abdulrazzaq et al. 2002; Lauer et al. 2018; Shuaib et al. 2010c) and found no evidence for an increased likelihood of these adverse pregnancy outcomes, albeit the trend went in this direction. However, considering the limited number of adverse events in these studies, they may have been underpowered. In terms of AF exposure and development of neonatal jaundice, there was some evidence of a detrimental effect despite limited sample sizes, with two out of four studies finding a clear increase and the other two trends in this direction.

There is comparatively good evidence for an adverse effect of maternal AF exposure on fetal growth, resulting in decreased mean birth weight and increased risk of low birth weight among exposed newborns. Two studies found this negative relationship only in female newborns. The others did not report sex-stratified results. It is noteworthy that two of the more recent studies that considered levels of AF exposure found a dose-response effect between AF exposure and fetal growth. However, almost half of the included studies did not sufficiently adjust for other known risk factors for intrauterine growth restriction such as maternal infections, maternal age, and socioeconomic status, which may be associated with AF exposure in pregnancy and thus lead to confounding. Nevertheless, the consistent evidence from animal studies of adverse effects of AFs on fetal growth, as well as on preterm deliveries and miscarriages (Ibeh and Saxena 1997; Ray et al. 1986; Wang et al. 2016), suggest that the observed associations in the studies reviewed are probably not just due to residual confounding.

Plausible biological mechanisms linking maternal exposure to Aspergillus mycotoxins to adverse pregnancy 
outcomes such as maternal anemia and intrauterine growth restriction have been previously described (Smith et al. 2017). Smith et al. (2017) suggest that mycotoxins affect pregnancy outcomes through three main pathways in both mother and fetus: (i) upregulation of pro-inflammatory cytokines and/ or downregulation of anti-inflammatory cytokines, (ii) induction of enteropathy characterized by intestinal inflammation and impaired placental and fetal development, and (iii) toxic effects on fetal organs causing inflammation and impaired fetal development. Toxic effects of AFs on the newborn's liver coupled with increased hemolysis of fetal hemoglobin may partly explain the apparent association between fetal AF exposure and neonatal jaundice. Teratogenic effects of OTA have also been documented in animals, with craniofacial abnormalities being the most frequently observed, alongside reduced birth weight (Malir et al. 2013). These harmful effects were shown to be potentiated by the presence of other mycotoxins or contaminants (Malir et al. 2013).

\section{Fusarium mycotoxins and adverse pregnancy outcomes}

Various animal studies have linked adverse pregnancy outcomes such as neural tube defect and growth suppression to exposure to Fusarium mycotoxins (Gelineau-van Waes et al. 2012; Wolf and Horugel 1994). For example, there is strong evidence that FBs disrupt the biosynthesis of sphingolipids, vital structures in cell membranes, which interferes with folate receptors, affecting folate bioavailability and ultimately causing neural tube defects (Gelineau-van Waes et al. 2012; Marasas et al. 2004). In addition, there is evidence on the mechanism of toxicity of DON through its ability to inhibit ribosomal protein synthesis, as well as inducing systemic immune activation and alterations in the growth hormone system (Pestka 2010; Rotter et al. 1996).

This review found no human studies on maternal or fetal exposure to DON or ZEN and adverse pregnancy outcomes. This may partly be due to lack of valid biomarkers to accurately measure these exposures. Nonetheless, two studies were identified which evaluated maternal FB exposure and adverse pregnancy outcomes among maize-consuming populations in South Africa (Moodley et al. 2001) and North America (Missmer et al. 2006). These studies found an association with maternal exposure to FBs and increased occurrence of neural tube defect (Missmer et al. 2006) and pre-eclampsia and eclampsia (Moodley et al. 2001). The study by Moodley et al. (2001) assessed maternal exposure from the reported total number of corn tortillas consumed during the first trimester of pregnancy, which has potential for recall bias, but also used an objective measure of FB exposure obtained from maternal blood. Even though the findings of Missmer et al. are suggestive of a plausible association between maternal FB exposure and an increased occurrence of neural tube defect, temporality of recruitment and blood collection is arguably an important limitation. Animal studies suggest that following an exposure to a high dose of FBs, even sub-toxic doses will maintain an elevated sphinganine level (Enongene et al. 2002; Wang et al. 1999). Thus, postpartum levels might adequately reflect pregnancy levels if study participants are chronically exposed to FBs - a plausible situation in the study setting. Nevertheless, more rigorous prospective studies are needed to establish the effects of Fusarium mycotoxins on pregnancy outcomes.

\section{Proxy measures of mycotoxin exposure}

While animal studies show a clear effect of mycotoxin exposure on pregnancy loss or miscarriage, there is limited evidence in humans. This may reflect a scarcity of methodologically rigorous pregnancy and birth surveillance systems to provide the needed information. Several large studies using grain farming and fungal warnings as proxy measures for mycotoxin exposure found associations with late-term miscarriage and mid-pregnancy deliveries. In contrast, studies measuring blood biomarkers of AFs were unable to provide evidence on any effects on preterm delivery or gestational age. These studies were mostly small, recruited women in late pregnancy, and lacked appropriate pregnancy and birth surveillance systems. Ideally, to ascertain true scientific evidence for the effect of mycotoxins on adverse pregnancy outcomes, a study will require a detailed record of events happening during the pregnancy period including all potential factors that my influence pregnancy outcomes. This is often impossible in most study settings. The availability of linked data, such as those provided by the Medical Birth Registry of Norway used in the proxy measures of mycotoxin exposure studies included, helps overcome this limitation and may partly explain the differences in findings. Furthermore, the small studies that used blood mycotoxin biomarkers also evaluated the effect of a single mycotoxin (AFs), rather than the effect of exposure to multiple mycotoxins as occurs in reality, which may be reflected by the proxy measures.

In Norway, where the proxy exposure studies were conducted, a recent study applying a semi-quantitative multimycotoxin analysis of grain grown in favorable fungal climatic conditions confirmed a high prevalence of multimycotoxin contamination (Uhlig et al. 2013). Nevertheless, the results from proxy measures are limited as they do not measure quantitatively the various mycotoxins present and also cannot examine how these mycotoxins may interact to influence adverse pregnancy outcomes. Furthermore, an aggregated area-level measure of possible mycotoxin exposure is an imperfect reflection of individual women's exposures during pregnancy. 
The differences in the prevailing types of mycotoxins in Norway and the African region may also partly explain the differences in findings from the proxy studies from Norway and the studies from Africa. For example, while the studies from Africa reflect a high prevalence of Aspergillus mycotoxins such as AFs, the study by Uhlig and colleagues showed a rather high prevalence and concentrations of Fusarium mycotoxins such as DON, FB, and ZEN in grain grown under exceptional climatic conditions in Norway (Uhlig et al. 2013).

\section{Strengths and limitations of this review}

To our knowledge, this is the first systematic review synthesizing available epidemiologic evidence on mycotoxin exposure and pregnancy outcomes. Multiple relevant databases were systematically searched for relevant studies without the use of "filters" and language restrictions. Two researchers used predefined criteria to independently assess the eligibility of the identified studies and furthermore comprehensively assessed the quality of the included studies. Our systematic review considered a wide range of pregnancy outcomes, and the study was conducted in accordance with established guidelines for conducting systematic reviews.

Our study is however not without limitations. First, systematic reviews generally suffer from selective reporting of the original studies, given that null associations are often not published. Hence, selection bias cannot be ruled out. Second, this review unfortunately could not pool the results in a metaanalysis to estimate the effect of various mycotoxins on adverse pregnancy outcomes, because the included studies examined different mycotoxins and outcomes and their effect measures were differently reported, often without sufficient information for pooling.

In conclusion, fetal exposure to mycotoxins is widespread, especially in tropical low-income countries, indicating frequent mold contamination of maternal diets. In spite of this, there are relatively few epidemiological studies investigating the effects of mycotoxins on the occurrence of adverse pregnancy outcomes. Our systematic review, which synthesized the few available studies, found evidence for detrimental effects of (a) maternal exposure to AFs on intrauterine growth, potentially more so in girls, (b) fetal AF exposure on the development of neonatal jaundice, (c) maternal exposure to FBs on the development of hypertensive disease in pregnancy and neural tube defects, and (d) exposure to mycotoxins as measured through grain farming and weather conditions on preterm birth and late-term miscarriage.

More prospective studies, using pregnancy and birth surveillance systems or using linked databases, are still needed to firmly establish the effects of mycotoxin exposure on adverse pregnancy outcomes in humans. In particular, studies should take advantage of recent development in biomarker analysis, enabling relatively easy and objective measurement of multiple different mycotoxins that constitute real-life exposure.

Funding information Open Access funding provided by Projekt DEAL. Sabine Gabrysch is paid by Heidelberg University, the Potsdam Institute for Climate Impact Research via Charité-Universitätsmedizin Berlin and supported by a research grant from the German Ministry of Education and Research (BMBF). Nicholas Kyei did this work as part of his doctoral thesis supported by the GNPC foundation PhD Fellowship.

\section{Compliance with ethical standards}

Disclaimer The funders had no role in the study design, data collection and analysis, decision to publish, or preparation of the manuscript.

Conflict of interest The authors declare that they have no conflict of interest.

Open Access This article is licensed under a Creative Commons Attribution 4.0 International License, which permits use, sharing, adaptation, distribution and reproduction in any medium or format, as long as you give appropriate credit to the original author(s) and the source, provide a link to the Creative Commons licence, and indicate if changes were made. The images or other third party material in this article are included in the article's Creative Commons licence, unless indicated otherwise in a credit line to the material. If material is not included in the article's Creative Commons licence and your intended use is not permitted by statutory regulation or exceeds the permitted use, you will need to obtain permission directly from the copyright holder. To view a copy of this licence, visit http://creativecommons.org/licenses/by/4.0/.

\section{References}

Abdulrazzaq YM, Osman N, Ibrahim A (2002) Fetal exposure to aflatoxins in the United Arab Emirates. Ann Trop Paediatr 22:3-9. https://doi.org/10.1179/027249302125000094

Abdulrazzaq YM, Osman N, Yousif ZM, Trad O (2004) Morbidity in neonates of mothers who have ingested aflatoxins. Ann Trop Paediatr 24:145-151. https://doi.org/10.1179/ 027249304225013420

Abid S, Hassen W, Achour A, Skhiri H, Maaroufi K, Ellouz F, Creppy E, Bacha H (2003) Ochratoxin a and human chronic nephropathy in Tunisia: is the situation endemic? Hum Exp Toxicol 22:77-84. https://doi.org/10.1191/0960327103ht328oa

Abulu EO, Uriah N, Aigbefo HS, Oboh PA, Agbonlahor DE (1998) Preliminary investigation on aflatoxin in cord blood of jaundiced neonates. West Afr J Med 17:184-187

Ahmed H, Hendrickse RG, Maxwell SM, Yakubu AM (1995) Neonatal jaundice with reference to aflatoxins: an aetiological study in Zaria, northern Nigeria. Ann Trop Paediatr 15:11-20

Ali N, Blaszkewicz M, Al Nahid A, Rahman M, Degen GH (2015) Deoxynivalenol exposure assessment for pregnant women in Bangladesh. Toxins 7:3845-3857. https://doi.org/10.3390/ toxins 7103845

Ali N, Blaszkewicz M, Manirujjaman M, Degen GH (2016) Biomonitoring of concurrent exposure to ochratoxin a and citrinin in pregnant women in Bangladesh. Mycotoxin Res 32:163-172. https://doi.org/10.1007/s12550-016-0251-0

Ali N, Blaszkewicz M, Hossain K, Degen GH (2017) Determination of aflatoxin $\mathrm{M}_{1}$ in urine samples indicates frequent dietary exposure to 
aflatoxin $\mathrm{B}_{1}$ in the Bangladeshi population. Int $\mathrm{J}$ Hyg Environ Health 220:271-281. https://doi.org/10.1016/j.ijheh.2016.11.002

Alizadeh AM, Rohandel G, Roudbarmohammadi S, Roudbary M, Sohanaki H, Ghiasian SA, Taherkhani A, Semnani S, Aghasi M (2012) Fumonisin $B_{1}$ contamination of cereals and risk of esophageal cancer in a high risk area in northeastern Iran. Asian Pac J Cancer Prev 13:2625-2628. https://doi.org/10.7314/apjcp.2012.13. 6.2625

Bennett JW, Klich M (2003) Mycotoxins. Clin Microbiol Rev 16:497516. https://doi.org/10.1128/CMR.16.3.497-516.2003

Carlos RLJ, Leticia IG, Efrain FSE, Miguel RA (2014) Aflatoxigenic feeding and its possible implications after pregnancy. Biomed Pharmacol J 7:183-193. https://doi.org/10.13005/bpj/471

CAST (2003) Mycotoxins: risks in plant, animal, and human systems vol Task Force report no.139. CAST: Council for Agricultural Science and Technology, Ames

Chan-Hon-Tong A, Charles MA, Forhan A, Heude B, Sirot V (2013) Exposure to food contaminants during pregnancy. Sci Total Environ 458:27-35. https://doi.org/10.1016/j.scitotenv.2013.03.100

Chu FS, Li GY (1994) Simultaneous occurrence of fumonisin $B_{1}$ and other mycotoxins in moldy corn collected from the People's republic of China in regions with high incidences of esophageal cancer. Appl Environ Microbiol 60:847-852

De Vries HR, Maxwell SM, Hendrickse RG (1989) Foetal and neonatal exposure to aflatoxins. Acta Paediatr Scand 78:373-378

Enongene EN, Sharma RP, Bhandari N, Miller JD, Meredith FI, Voss KA (2002) Riley RT, Persistence and reversibility of the elevation in free sphingoid bases induced by fumonisin inhibition of ceramide synthase. Toxicol Sci 67:173 -181. https://doi.org/10.1093/toxsci/67.2. 173

Escriva L, Font G, Manyes L, Berrada H (2017) Studies on the presence of mycotoxins in biological samples: an overview. Toxins:9. https:// doi.org/10.3390/toxins9080251

Etzel RA (2014) Reducing malnutrition: time to consider potential links between stunting and mycotoxin exposure? Pediatrics 134:4-6. https://doi.org/10.1542/peds.2014-0827

FAO (2019) FAO, IFAD, UNICEF, WFP and WHO. The state of food security and nutrition in the world 2019. Safeguarding against economic slowdowns and downturns. Food and Agriculture Organization, Rome

Gelineau-van Waes J, Rainey MA, Maddox JR, Voss KA, Sachs AJ, Gardner NM, Wilberding JD, Riley RT (2012) Increased sphingoid base-1-phosphates and failure of neural tube closure after exposure to fumonisin or FTY720 birth defects research part a. Birth Defects Res A Clin Mol Teratol 94:790-803. https://doi.org/10.1002/bdra. 23074

Gong Y, Hounsa A, Egal S, Turner PC, Sutcliffe AE, Hall AJ, Cardwell K, Wild CP (2004) Postweaning exposure to aflatoxin results in impaired child growth: a longitudinal study in Benin, West Africa. Environ Health Perspect 112:1334-1338. https://doi.org/10.1289/ ehp. 6954

Groopman JD, Egner PA, Schulze KJ et al (2014) Aflatoxin exposure during the first 1000 days of life in rural South Asia assessed by aflatoxin $\mathrm{B}_{1}$-lysine albumin biomarkers. Food Chem Toxicol 74: 184-189

Hope JH, Hope BE (2012) A review of the diagnosis and treatment of ochratoxin a inhalational exposure associated with human illness and kidney disease including focal segmental glomerulosclerosis. J Environ Public Health 2012:835059. https://doi.org/10.1155/2012/ 835059

IARC (2015) In: Wild CP, Miller JD, Groopman JD (eds) Mycotoxin control in low- and middle-income countries. International Agency for Research on Cancer, Lyon (FR)

Ibeh IN, Saxena DK (1997) Aflatoxin $B_{1}$ and reproduction. I. Reproductive performance in female rats. Afr J Reprod Health 1: $79-84$
Jonsyn FE, Maxwell SM, Hendrickse RG (1995) Human fetal exposure to ochratoxin a and aflatoxins. Ann Trop Paediatr 15:3-9

Kramer MS (2003) The epidemiology of adverse pregnancy outcomes: an overview. J Nutr 133:1592s-1596s. https://doi.org/10.1093/jn/ 133.5.1592S

Kristensen P, Irgens LM, Andersen A, Bye AS, Sundheim L (1997) Gestational age, birth weight, and perinatal death among births to Norwegian farmers, 1967-1991. Am J Epidemiol 146:329-338

Kristensen P, Andersen A, Irgens LM (2000) Hormone-dependent cancer and adverse reproductive outcomes in farmers' families-effects of climatic conditions favoring fungal growth in grain. Scand J Work Environ Health 26:331-337

Lauer JM, Duggan CP, Ausman LM, Griffiths JK, Webb P, Wang J-S, Xue KS, Agaba E, Nshakira N, Ghosh S (2018) Maternal aflatoxin exposure during pregnancy and adverse birth outcomes in Uganda. Matern Child Nutr:e12701. https://doi.org/10.1111/men.12701

Liberati A, Altman DG, Tetzlaff J, Mulrow C, Gotzsche PC, Ioannidis JPA, Clarke M, Devereaux PJ, Kleijnen J, Moher D (2009) The PRISMA statement for reporting systematic reviews and metaanalyses of studies that evaluate health care interventions: explanation and elaboration. PLoS Med 6:2-28

Malir F, Ostry V, Pfohl-Leszkowicz A, Novotna E (2013) Ochratoxin a: developmental and reproductive toxicity-an overview. Birth Defects Res B Dev Reprod Toxicol 98:493-502

Marasas WF, Riley RT, Hendricks KA et al (2004) Fumonisins disrupt sphingolipid metabolism, folate transport, and neural tube development in embryo culture and in vivo: a potential risk factor for human neural tube defects among populations consuming fumonisincontaminated maize. J Nutr 134:711-716. https://doi.org/10.1093/ jn/134.4.711

Maxwell SM, Familusi JB, Sodeinde O, Chan MC, Hendrickse RG (1994) Detection of naphthols and aflatoxins in Nigerian cord blood. Ann Trop Paediatr 14:3-5

McMillan A, Renaud JB, Burgess KMN, Orimadegun AE, Akinyinka OO, Allen SJ, Miller JD, Reid G, Sumarah MW (2018) Aflatoxin exposure in Nigerian children with severe acute malnutrition. Food Chem Toxicol 111:356-362. https://doi.org/10.1016/j.fct.2017.11.030

Missmer SA, Suarez L, Felkner M, Wang E, Merrill AH Jr, Rothman KJ, Hendricks KA (2006) Exposure to fumonisins and the occurrence of neural tube defects along the Texas-Mexico border. Environ Health Perspect 114:237-241

Moodley J, Moodley D, Reddy L, Dutton MF, Chuturgoon AA (2001) Fumonisin $\mathrm{B}_{1}$ : an aetiological role in pre-eclampsia. $\mathrm{J}$ Obstet Gynaecol 21:599-600. https://doi.org/10.1080/01443610120085555

Morgan RL, Whaley P, Thayer KA, Schunemann HJ (2018) Identifying the PECO: a framework for formulating good questions to explore the association of environmental and other exposures with health outcomes. Environ Int 121:1027-1031. https://doi.org/10.1016/j. envint.2018.07.015

Nordby KC, Irgens LM, Kristensen P (2006) Immunological exposures in Norwegian agriculture and pre-eclampsia. Paediatr Perinat Epidemiol 20:462-470. https://doi.org/10.1111/j.1365-3016.2006. 00761.x

Ota E, Ganchimeg T, Morisaki N, Vogel JP, Pileggi C, Ortiz-Panozo E, Souza JP, Mori R (2014) Risk factors and adverse perinatal outcomes among term and preterm infants born small-for-gestationalage: secondary analyses of the WHO Multi-Country Survey on Maternal and Newborn Health. PLoS One 9(8):e105155

Pestka JJ (2010) Deoxynivalenol: mechanisms of action, human exposure, and toxicological relevance. Arch Toxicol 84:663-679. https:// doi.org/10.1007/s00204-010-0579-8

Raghubeer S, Nagiah S, Chuturgoon AA (2017) Acute ochratoxin a exposure induces inflammation and apoptosis in human embryonic kidney (HEK293) cells. Toxicon 137:48-53. https://doi.org/10. 1016/j.toxicon.2017.07.013 
Ray AC, Abbitt B, Cotter SR, Murphy MJ, Reagor JC, Robinson RM, West JE, Whitford HW (1986) Bovine abortion and death associated with consumption of aflatoxin-contaminated peanuts. J Am Vet Med Assoc 188:1187-1188

Richard JL (2007) Some major mycotoxins and their mycotoxicoses-an overview. Int J Food Microbiol 119:3-10. https://doi.org/10.1016/j. ijfoodmicro.2007.07.019

Rotter BA, Prelusky DB, Pestka JJ (1996) Toxicology of deoxynivalenol (vomitoxin). J Toxicol Environ Health 48:1-34. https://doi.org/10. 1080/713851046

Shuaib FM, Ehiri J, Abdullahi A, Williams JH, Jolly PE (2010a) Reproductive health effects of aflatoxins: a review of the literature. Reprod Toxicol 29:262-270

Shuaib FM, Jolly PE, Ehiri JE, Jiang Y, Ellis WO, Stiles JK, Yatich NJ, Funkhouser E, Person SD, Wilson C, Williams JH (2010b) Association between anemia and aflatoxin $\mathrm{B}_{1}$ biomarker levels among pregnant women in Kumasi, Ghana. Am J Trop Med Hyg 83:1077-1083. https://doi.org/10.4269/ajtmh.2010.09-0772

Shuaib FM, Jolly PE, Ehiri JE, Yatich N, Jiang Y, Funkhouser E, Person SD, Wilson C, Ellis WO, Wang JS, Williams JH (2010c) Association between birth outcomes and aflatoxin $\mathrm{B}_{1}$ biomarker blood levels in pregnant women in Kumasi, Ghana. Tropical Med Int Health 15:160-167. https://doi.org/10.1111/j.1365-3156.2009. 02435.x

Smith LE, Stoltzfus RJ, Prendergast A (2012) Food chain mycotoxin exposure, gut health, and impaired growth: a conceptual framework. Adv Nutr 3:526-531. https://doi.org/10.3945/an.112.002188

Smith LE, Prendergast AJ, Turner PC, Humphrey JH, Stoltzfus RJ (2017) Aflatoxin exposure during pregnancy, maternal anemia, and adverse birth outcomes. Am J Trop Med Hyg 96:770-776. https://doi.org/ 10.4269/ajtmh.16-0730

Sodeinde O, Chan MCK, Maxwell SM, Familusi JB, Hendrickse RG (1995) Neonatal jaundice, aflatoxins and naphthols: report of a study in Ibadan, Nigeria. Ann Trop Paediatr 15:107-113. https://doi.org/ 10.1080/02724936.1995.11747757
Turner PC, Collinson AC, Cheung YB, Gong Y, Hall AJ, Prentice AM, Wild CP (2007) Aflatoxin exposure in utero causes growth faltering in Gambian infants. Int J Epidemiol 36:1119-1125. https://doi.org/ 10.1093/ije/dym 122

Turner PC, Flannery B, Isitt C, Ali M, Pestka J (2012) The role of biomarkers in evaluating human health concerns from fungal contaminants in food. Nutr Res Rev 25:162-179

Uhlig S, Eriksen GS, Hofgaard IS, Krska R, Beltran E, Sulyok M (2013) Faces of a changing climate: semi-quantitative multi-mycotoxin analysis of grain grown in exceptional climatic conditions in Norway. Toxins 5:1682-1697. https://doi.org/10.3390/ toxins 5101682

Wang E, Riley RT, Meredith FI, Merrill AH Jr (1999) Fumonisin B consumption by rats causes reversible, dose-dependent increases in urinary sphinganine and sphingosine. J Nutr 129:214-220. https:// doi.org/10.1093/jn/129.1.214

Wang H, Wei H, Ma J, Luo X (2000) The fumonisin $\mathrm{B}_{1}$ content in corn from North China, a high-risk area of esophageal cancer. J Environ Pathol Toxicol Oncol 19:139-141

Wang Y, Tan W, Wang CC, Leung LK (2016) Exposure to aflatoxin $B_{1}$ in late gestation alters protein kinase $\mathrm{C}$ and apoptotic protein expression in murine placenta. Reprod Toxicol 61:68-74. https://doi.org/ 10.1016/j.reprotox.2016.03.001

Wells GA, O'Connell D, Peterson J, Welch V, Losos M, Tugwell P (n.d.) The Newcastle-Ottawa Scale (NOS) for assessing the quality of nonrandomised studies in meta-analyses. http://www.ohri.ca/ programs/clinical_epidemiology/oxford.asp. Accessed 10 May 2017

Wolf H, Horugel K (1994) Observations on fusarium toxins and their effects on fertility and litter performance of sows. Monatshefte für Veterinärmedizin 49(5):207-211

Publisher's note Springer Nature remains neutral with regard to jurisdictional claims in published maps and institutional affiliations. 